\author{
Marquette University \\ e-Publications@Marquette
}

7-1998

\title{
Graft Copolymerization of Methacrylic Acid, Acrylic Acid and Methyl Acrylate onto Styrene-Butadiene Block Copolymer
}

David D. Jiang

Marquette University

Charles Wilkie

Marquette University, charles.wilkie@marquette.edu

Follow this and additional works at: https://epublications.marquette.edu/chem_fac

Part of the Chemistry Commons

\section{Recommended Citation}

Jiang, David D. and Wilkie, Charles, "Graft Copolymerization of Methacrylic Acid, Acrylic Acid and Methyl Acrylate onto Styrene-Butadiene Block Copolymer" (1998). Chemistry Faculty Research and Publications. 756.

https://epublications.marquette.edu/chem_fac/756 
Marquette University

e-Publications@Marquette

\title{
Chemistry Faculty Research and Publications/College of Arts and Sciences
}

This paper is NOT THE PUBLISHED VERSION; but the author's final, peer-reviewed manuscript. The published version may be accessed by following the link in the citation below.

European Polymer Journal, Vol. 34, No. 7 (1998): 997-1006. DOI. This article is @ Elsevier and permission has been granted for this version to appear in e-Publications@Marquette. Elsevier does not grant permission for this article to be further copied/distributed or hosted elsewhere without the express permission from Elsevier.

\section{Graft copolymerization of methacrylic acid, acrylic acid and methyl acrylate onto styrene-butadiene block copolymer}

David D. Jiang

Department of Chemistry, Marquette University, Milwaukee, WI

Charles A. Wilkie

Department of Chemistry, Marquette University, Milwaukee, WI

\begin{abstract}
Methyl acrylate, methacrylic acid, and acrylic acid have been graft copolymerized onto styrenebutadiene block copolymer. All three monomers react through the macroradical interacting with the double bond of butadiene. The site of reaction has been established by infrared spectroscopy. For methyl acrylate every unit of the styrene-butadiene block copolymer is grafted but only a small fraction is grafted when the acids are used. The difference apparently lies in the fact that the reaction with the ester is homogeneous while with the acids the reactions are heterogeneous.
\end{abstract}




\section{Introduction}

Huang and Sundberg 1, 2, 3, 4 have recently published a study on the graft copolymerization of three monomers, styrene, benzyl methacrylate, and benzyl acrylate, onto cis-polybutadiene. In this kinetic study they have shown that two different processes may occur for graft copolymerization. Initiators such as benzoyl peroxide, BPO, can abstract allylic hydrogen atoms from polybutadiene while other initiators, notably azobisisobutyronitrile, AIBN, cannot abstract the hydrogen atom. Neither initiator appears to have significant reactivity towards addition of primary radicals to the double bond of the polybutadiene. The allylic radicals which are generated by hydrogen abstraction can initiate polymerization of reactive monomers such as styrene or methacrylates, leading to the formation of graft copolymers, but are unable to initiate the less reactive acrylates. Primary radicals from both initiators will initiate homopolymerization of monomers over a wide range of reactivity. Graft copolymerization will still occur for monomers which are not initiated by the allylic backbone radicals; this process occurs by addition of the growing polymeric radical to the polybutadiene double bonds, producing a saturated alkyl radical which is capable of further initiation of low reactivity monomers. This latter process for the formation of graft copolymers is not excluded when reactive monomers are used but it appears to make only a minor contribution to the graft copolymerization of reactive monomers. These results generally agree with what previous workers in this area have suggested. ${ }^{5,6,7}$, 8

In previous work from this laboratory, the graft copolymerization of various vinyl monomers onto butadiene-containing polymers such as styrene-butadiene block copolymers, SBS and K-resin, ${ }^{9}$ and acrylonitrile-butadiene-styrene terpolymer, $A B S,{ }^{10,11,12}$ has been studied. The reaction may be initiated by both photochemical ${ }^{9,10,11}$ and chemical processes. ${ }^{12} \mathrm{Graft}$ copolymerization may modify the properties of the polymer and increase the wettability or dyeability or change a hydrophobic polymer into one which has some hydrophilic character and these assessments have frequently been used as proof of graft copolymerization. ${ }^{13,14,15,16,17,18}$ It is clearly advantageous to be able to characterize the graft copolymer in some way so as to clearly identify the site at which the monomer becomes attached and the process by which the reaction occurs. It is also important to understand the parameters which control the extent of graft copolymerization so that a reproducible amount of material may be obtained.

In this paper the graft copolymerization of methyl acrylate, methacrylic acid, and acrylic acid onto styrene-butadiene block copolymer, SBS, are examined and these results are compared with the previous results which we have reported for the graft copolymerization of methyl methacrylate onto SBS. ${ }^{19}$ The extent of graft copolymerization, the site of reaction on the polymer, and the mode of reaction are all identified.

\section{Experimental}

\subsection{Materials}

The styrene-butadiene-styrene block copolymer, SBS, used in this work was supplied by Shell as Kraton D1102 and contains about 75\% butadiene. Solvents, monomeric methacrylic acid and acrylic acid, and benzoyl peroxide, BPO, were supplied by Aldrich Chemical; AIBN was obtained from Eastman Kodak. Methyl methacrylate was provided by Mathesson, Coleman and Bell. All monomers contain polymerization inhibitors; these were removed by passing the monomer through a column containing 
an inhibitor remover supplied by Aldrich. Infrared spectra were obtained both by transmission and attenuated total reflectance on a Mattson Galaxy fourier transform infrared spectrometer.

\subsection{Preparation of the graft copolymer}

To a $0.500 \mathrm{~g}$ sample of SBS dissolved in $20 \mathrm{ml}$ chloroform in a $50 \mathrm{ml}$ round bottom flask was added $0.50 \mathrm{ml}$ initiator, AIBN or BPO $(0.200 \mathrm{M}$ acetone solution), and $0.50 \mathrm{ml}$ monomer. The reaction was thermostatically controlled at $63^{\circ} \mathrm{C}$ and the solution was magnetically stirred; the reaction time was $2 \mathrm{~h}$ for the acids and between 3 and $12 \mathrm{~h}$ for the ester. The appearance of the reaction mixture depended on the monomer; when methyl acrylate was used, a clear solution was obtained. When the monomer was methacrylic acid, precipitation from the reaction mixture was observed after about 15 min; no precipitate was observed for acrylic acid but a cloudy solution was obtained at the conclusion of the reaction. The solution was cooled to room temperature and $20 \mathrm{ml}$ of methanol was added to precipitate the polymer which was recovered by filtration.

\subsection{Separation of the graft copolymer from homopolymers}

The reaction mixture may contain ungrafted SBS, the homopolymer of the monomer as well as the desired graft copolymer. Separation is achieved by alternating and repeated treatment with a solvent for each of the homopolymers. For the graft copolymerization of methyl acrylate, the homopolymer poly(methyl acrylate) dissolves in a 90:10 acetone:water mixture while the graft copolymer and SBS are insoluble. The absence of ungrafted SBS is proven since the entire sample will dissolve in acetone while SBS is acetone insoluble. The identity of each fraction which is recovered by solvent treatment is confirmed by infrared spectroscopy. For the graft copolymerization of the acids, any ungrafted SBS may be removed by treatment with chloroform; the homopolymers of the acids are soluble in both water and methanol and both were used to achieve the separation. The typical procedure was to soak the entire sample in $20 \mathrm{ml}$ of methanol for one hour; the homopolymers of the acids will dissolve while the SBS and graft copolymer are observed to swell. The sample was repeatedly centrifuged and the supernatant liquid was removed and replaced with new methanol; this was repeated at least five times. The solvent was removed from the soluble fraction and it was identified as the polymeric acid by infrared spectroscopy. The portion which was not soluble in methanol was dried, then treated with $15 \mathrm{ml}$ of chloroform for a minimum of two hours; fresh chloroform was added and the procedure was repeated at least three times. After drying at room temperature, the procedure was repeated, again using methanol to remove any acid homopolymer, then chloroform to remove ungrafted SBS. The entire procedure was also carried out using water (at the boiling point) instead of methanol (at room temperature); dissolution of the homopolymer in water requires a much longer time.

\subsection{Definitions of terms used in this paper}

\subsubsection{Weight gain (\%WG)}

Weight gain is defined as the difference between the mass of the whole sample $\left(W_{w}\right)$ after reaction and the mass of SBS

$\left(W_{0}\right)$ divided by the mass of SBS, and is shown in Eq. (1).

$\% W G=W_{W}-W_{0} W_{0} \times 100$

\subsubsection{Graft yield (\%GY)}

Graft yield is the difference between the mass of graft copolymer $\left(W_{\mathrm{g}}\right)$ and the mass of SBS $\left(W_{\mathrm{o}}\right)$ divided by the mass of SBS and is shown in Eq. (2). 


\subsubsection{Total conversion (\%TC)}

Total conversion of monomer is expressed in Eq. (3), $W_{\mathrm{w}}$ and $W_{\mathrm{o}}$ are defined above and $W_{\mathrm{m}}$ is the mass of monomer:

$\% G Y=W_{g}-W_{0} W_{0} \times 100$

\subsubsection{Graft efficiency (\%GE)}

Graft efficiency is the fraction of polymerized monomer which is converted to graft copolymer and is shown in Eq. (4):

$\% \mathrm{TC}=\mathrm{W}_{\mathrm{w}}-\mathrm{W}_{\mathrm{o}} \mathrm{W}_{\mathrm{m}} \times 100$

\section{Results and discussion}

\subsection{Graft copolymerization of methyl acrylate onto styrene-butadiene block copolymer}

\subsubsection{Weight gain}

Weight gain is a measure of the total amount of polymerization. For the graft copolymerization of methyl acrylate onto SBS, the reaction proceeds as a typical radical polymerization whether the reaction is initiated by BPO and AIBN. Fig. 1 shows the relationship between weight gain and concentration of BPO; there is a linear relationship between the weight gain and the square root of the initiator concentration. A similar relationship is observed when the initiator is AIBN. Weight gain also depends on the concentrations of monomer and SBS and the time and temperature of the reaction, An increase in the concentration of monomer or an increase in the reaction time or temperature leads to a higher weight gain; an increase in the concentration of SBS gives a lower weight gain. Similar results were observed for the graft copolymerization of methyl methacrylate onto SBS.

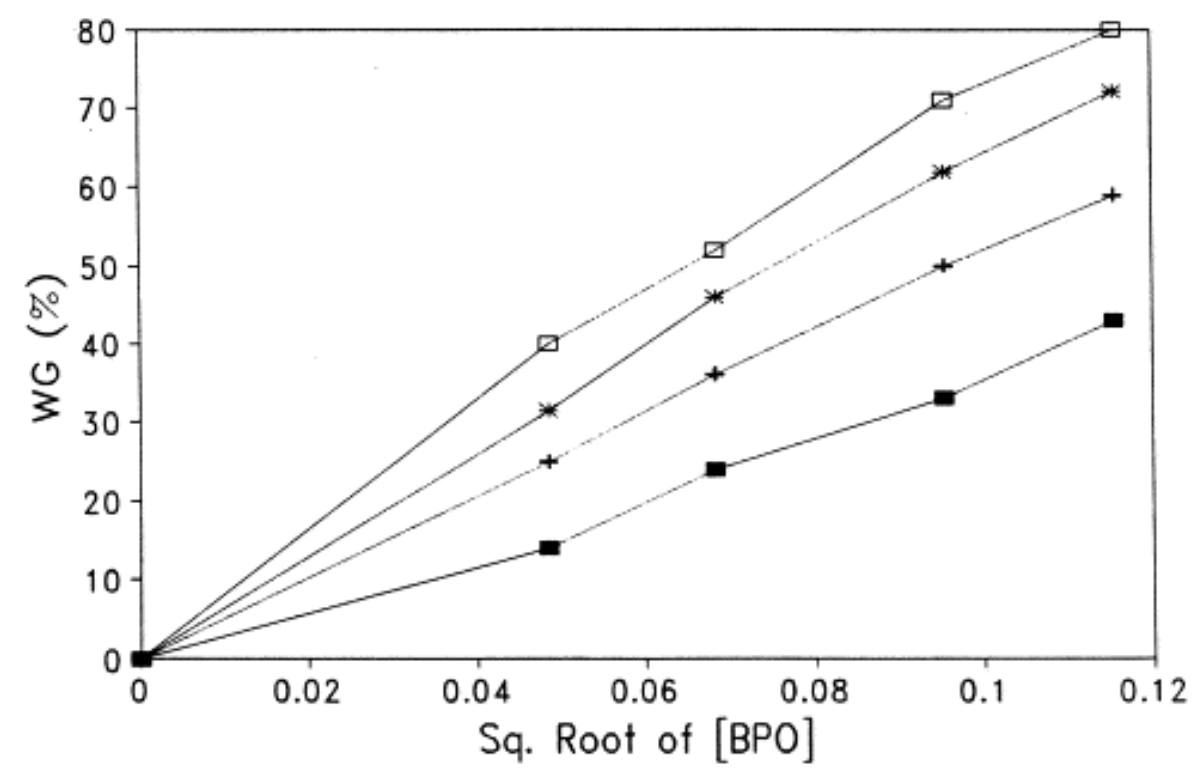

$$
-3 \mathrm{hrs}+6 \quad * 9 \quad \square 12
$$

Fig. 1. Weight gain as a function of square root of [BPO] for the graft copolymerization of methyl acrylate onto SBS in chloroform. [SBS] $=23 \mathrm{~g} / \mathrm{l},[\mathrm{MA}]=0.28 \mathrm{M}, 63^{\circ} \mathrm{C}$. 


\subsubsection{Total conversion}

The relationship between conversion and all the variables shows the same variations as are seen with weight gain. The fact that the conversion depends on the concentration of methyl acrylate must be emphasized because this is different than what is observed in the graft copolymerization of methyl methacrylate onto SBS; a plot of the conversion versus the concentration of methyl acrylate is shown in Fig. 2.

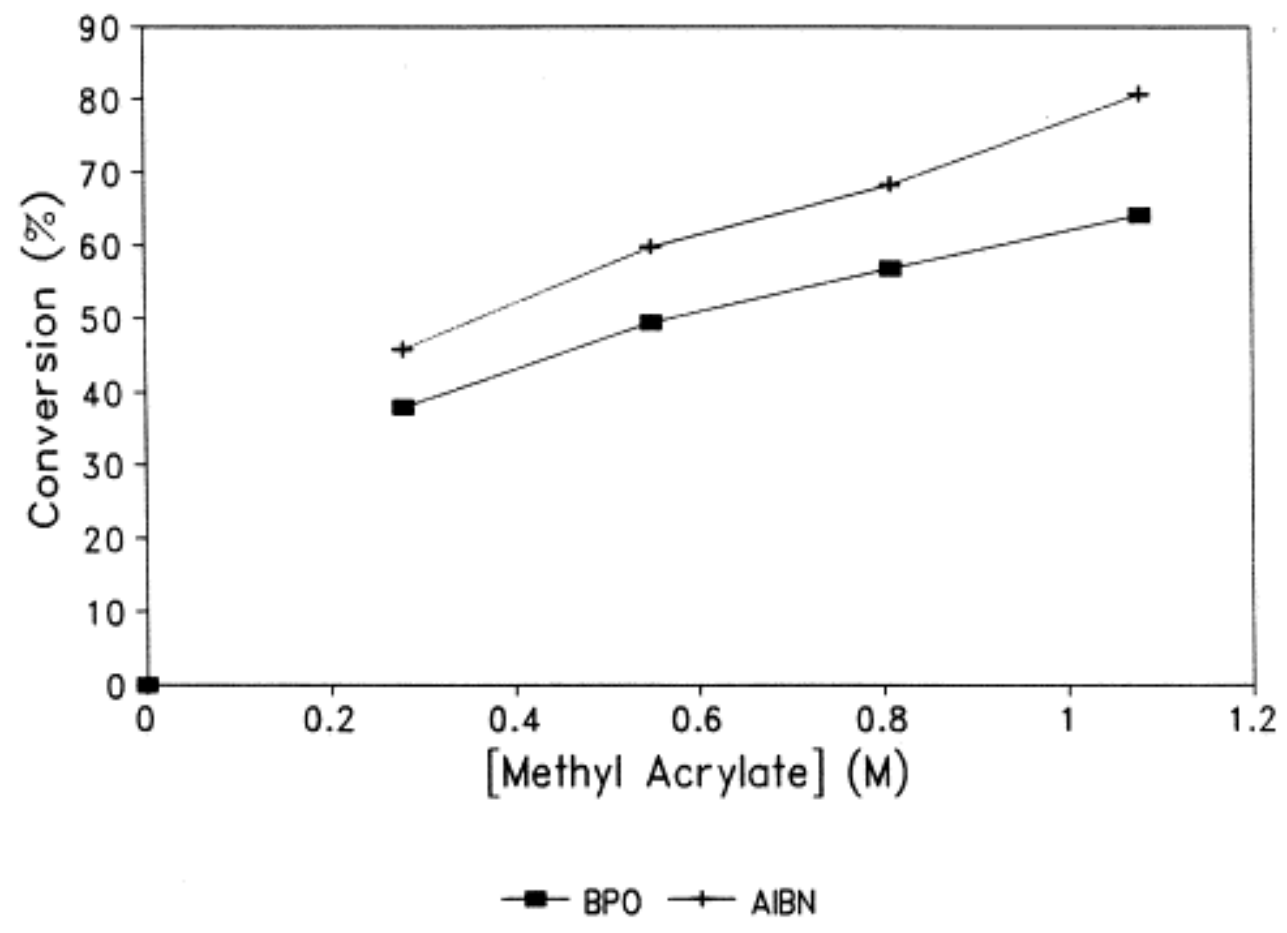

Fig. 2. Conversion vs [methyl acrylate] for the graft copolymerization of methyl acrylate onto SBS in chloroform. $[S B S]=23 \mathrm{~g} / \mathrm{l},[\mathrm{l}]=0.0047 \mathrm{M}, 6 \mathrm{~h}, 6^{\circ} \mathrm{C}$.

\subsubsection{Graft yield}

Graft yield reflects the formation of the graft copolymer; the graft yield shows a similar dependence to that of weight gain but the values are smaller. Fig. 3 shows the graft yield as a function of reaction time as well as concentration of monomer for the graft copolymerization of methyl acrylate onto SBS in chloroform initiated by BPO and AIBN. The graft yield increases with concentration of monomer and there is little difference in graft yield for AIBN and BPO as initiators. The graft yield usually increases with reaction time and monomer concentration but the observation that both AIBN and BPO are equally effective is different from what has been observed for the graft copolymerization of methyl methacrylate onto SBS where only BPO gives a significant graft yield and this suggests that a different reaction scheme occurs. 


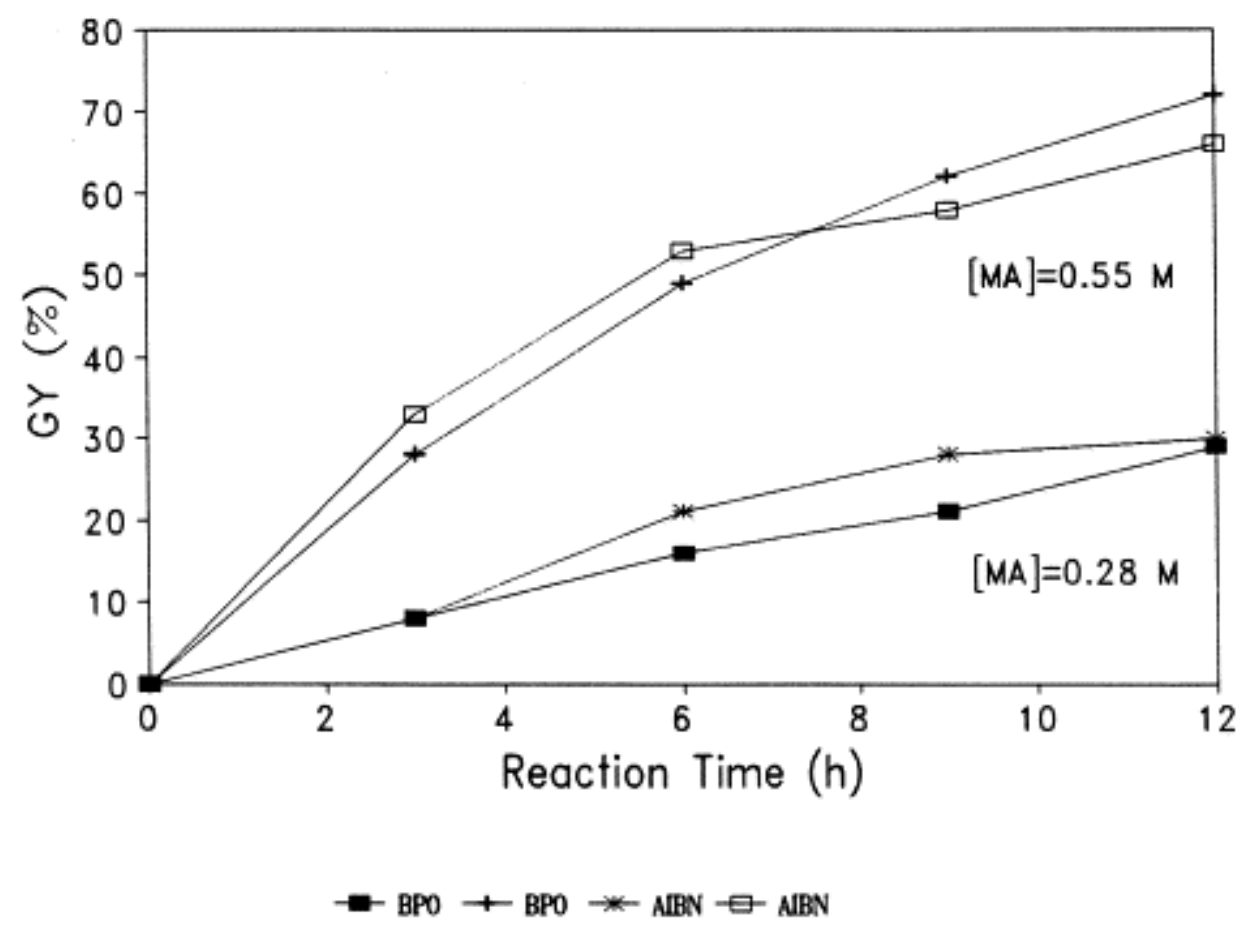

Fig. 3. Graft yield vs time and [methyl acrylate] for graft copolymerization of methyl acrylate onto SBS in chloroform. [SBS] $=23 \mathrm{~g} / \mathrm{l},[\mathrm{l}]=0.0047 \mathrm{M}, 63^{\circ} \mathrm{C}$.

\subsubsection{Graft efficiency}

Weight gain is a measure of both homopolymerization of the monomer and graft copolymerization of the monomer onto the polymer and graft yield provides information on the conversion of polymer into graft copolymer while graft efficiency is a measure of the extent of graft copolymerization relative to homopolymerization of the monomer. ${ }^{19}$ Graft efficiency is a function of the concentrations of SBS and initiator but is independent of the concentration of monomer and the time and temperature of reaction. In an investigation of graft copolymerization of benzyl acrylate onto cis-polybutadiene in benzene initiated by $A I B N$ at $60^{\circ} \mathrm{C}$, Huang and Sundberg ${ }^{2}$ reported that the graft efficiency has little relationship to the concentration of monomer, but does depend on initiator and backbone polymer concentration. Fig. 4 shows the monomer and time effect on the graft efficiency for the graft copolymerization of methyl acrylate onto SBS in chloroform using both AIBN and BPO as the initiator; this is plotted as the weight gain versus the graft yield and one can see that there is approximately a linear relationship between homopolymerization and graft copolymerization, i.e., as monomer undergoes reaction a constant fraction is converted to the graft copolymer. The concentration of methyl acrylate and the reaction time have little effect on the graft efficiency and there is not a significant difference in graft efficiency between BPO and AIBN. The effect of temperature on graft efficiency is shown in Fig. 5, this is similar to that of concentration of methyl acrylate and the reaction time. 


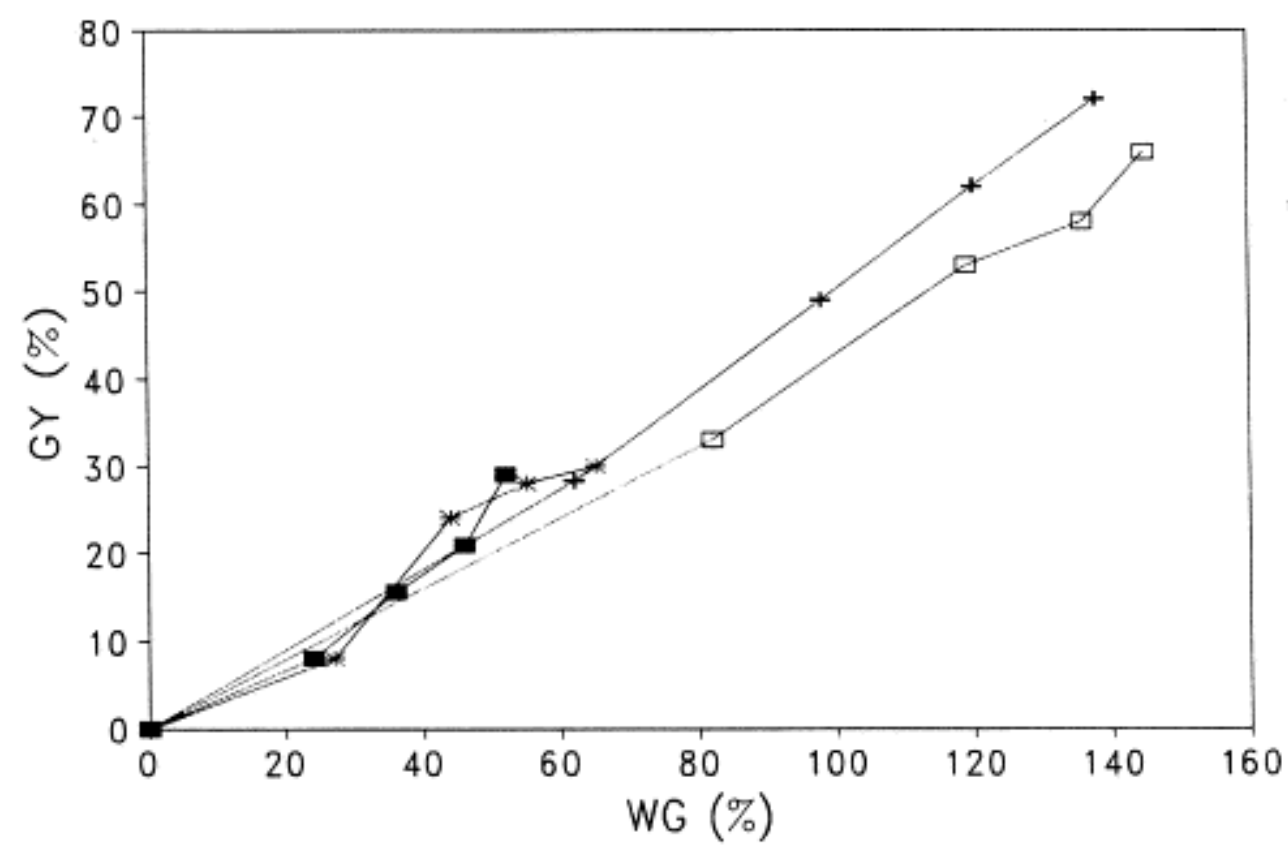

$\rightarrow-B P Q, \quad M A N=0.28 \mathrm{~N}+\mathrm{BPO}, \quad M M N=0.55 \mathrm{M} \rightarrow \mathrm{NBN}, \quad M N=0.28 \mathrm{~N} \boxminus \mathrm{AIBN}, \quad M A J=0.55 \mathrm{M}$

Fig. 4. Graft yield vs weight gain for graft copolymerization of methyl acrylate onto SBS in chloroform. [SBS] $=23 \mathrm{~g} / \mathrm{l},[\mathrm{l}]=0.0047 \mathrm{M}, 3-12 \mathrm{~h}, 63^{\circ} \mathrm{C}$.

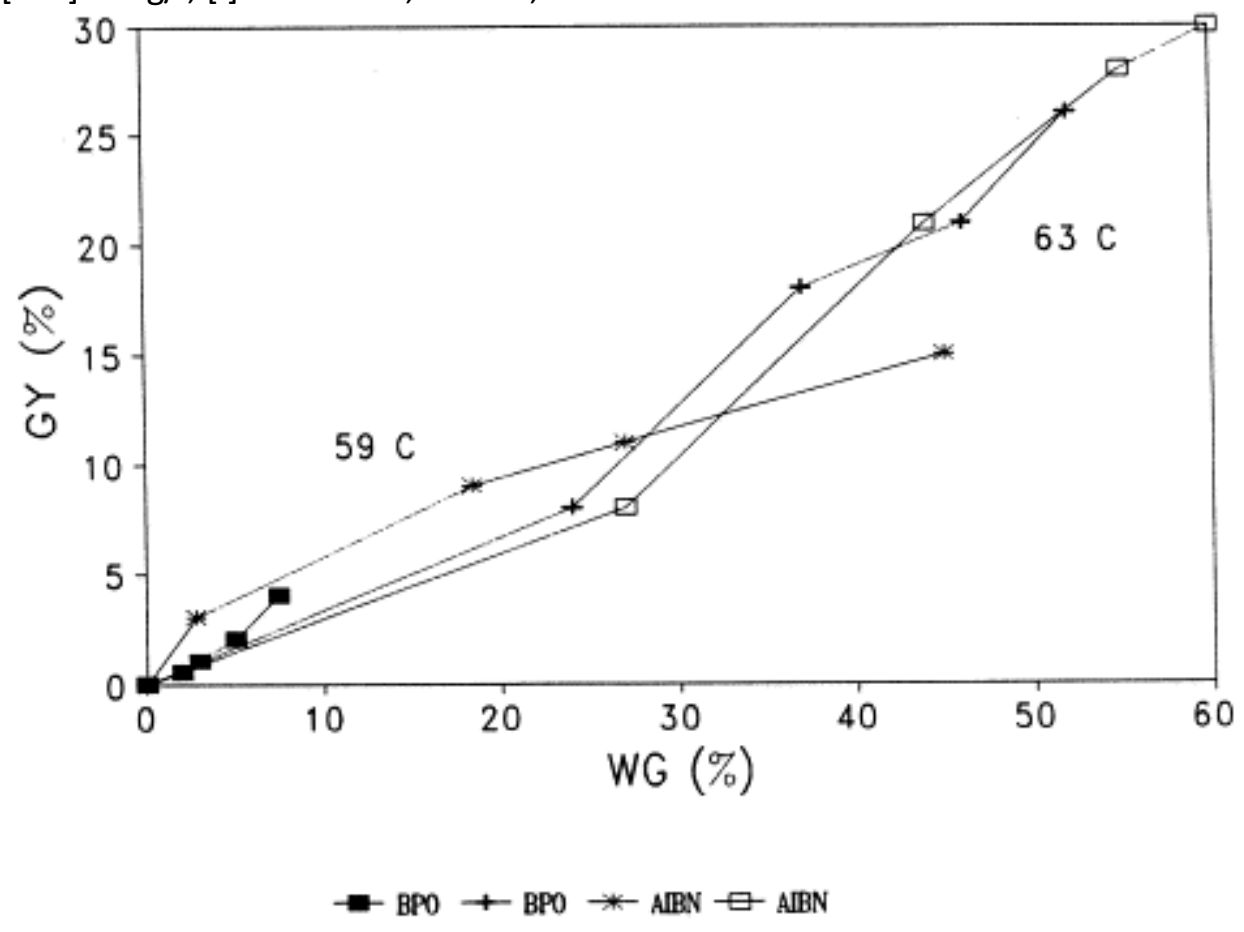

Fig. 5. Graft yield vs weight gain and temperature for graft copolymerization of methyl acrylate onto SBS in chloroform. $[\mathrm{SBS}]=23 \mathrm{~g} / \mathrm{l},[\mathrm{l}]=0.0047 \mathrm{M}, 3-12 \mathrm{~h}, 63^{\circ} \mathrm{C}$.

In order to see the overall relationship between the graft yield and weight gain, the data are plotted in one graph. Fig. 6 (for BPO initiation) and Fig. 7 (for AIBN initiation) show the overall effect of all the concentration variables except SBS concentration on the graft efficiency for the graft copolymerization of methyl acrylate onto SBS in chloroform. There is a linear relationship between the graft yield and 
weight gain. AIBN shows the same graft efficiency as BPO and the overall graft efficiency for both initiators is around 50\%; there is no initiator effect. Huang and Sundberg have also found that the extent of graft copolymerization does not depend on the initiator for the graft copolymerization of benzyl acrylate onto polybutadiene in benzene.

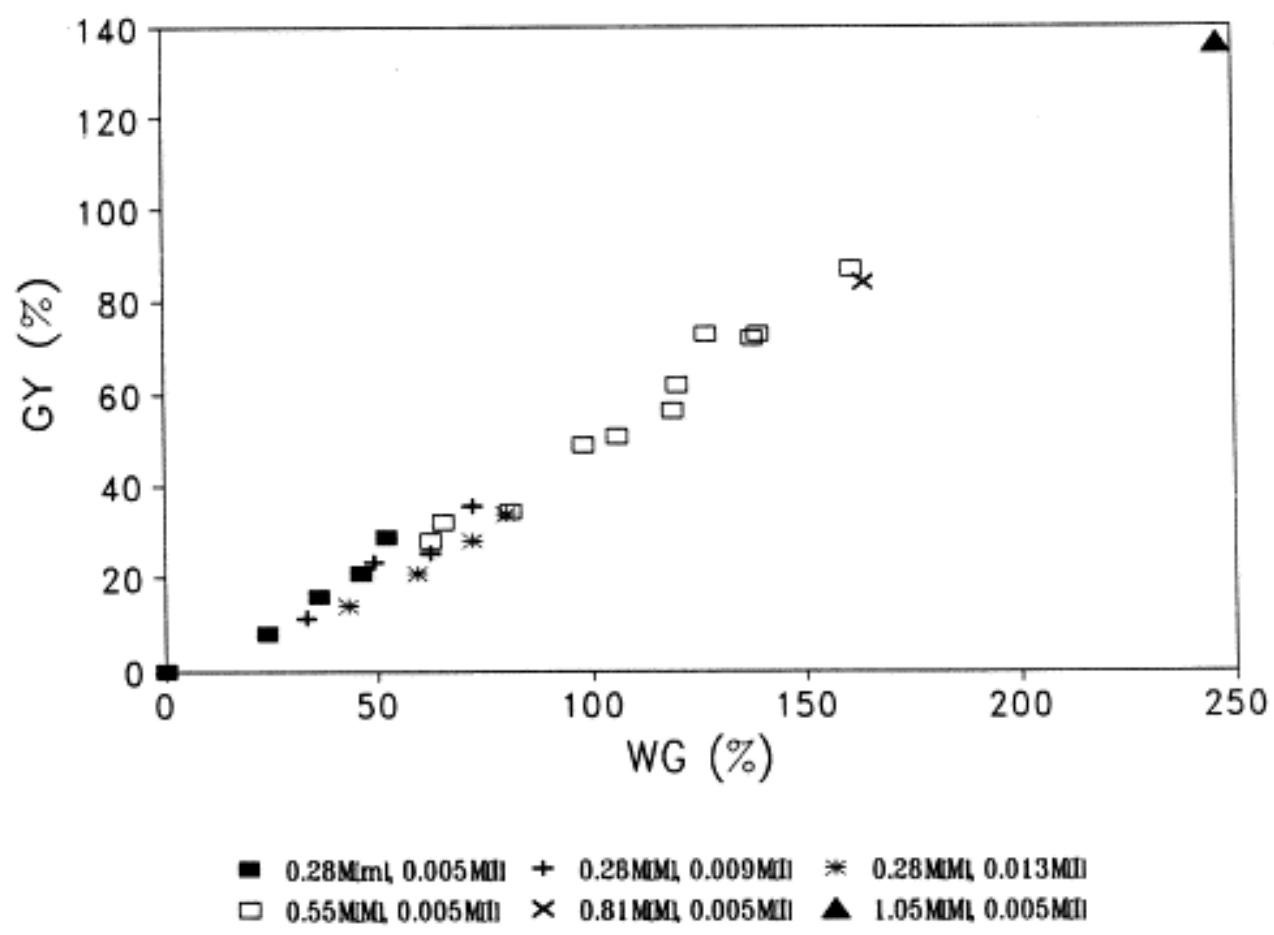

Fig. 6. Graft yield vs weight gain for the graft copolymerization of methyl acrylate onto SBS initiated by BPO in chloroform. [SBS] $=23 \mathrm{~g} / \mathrm{l}, 3-12 \mathrm{~h}, 63^{\circ} \mathrm{C}$.

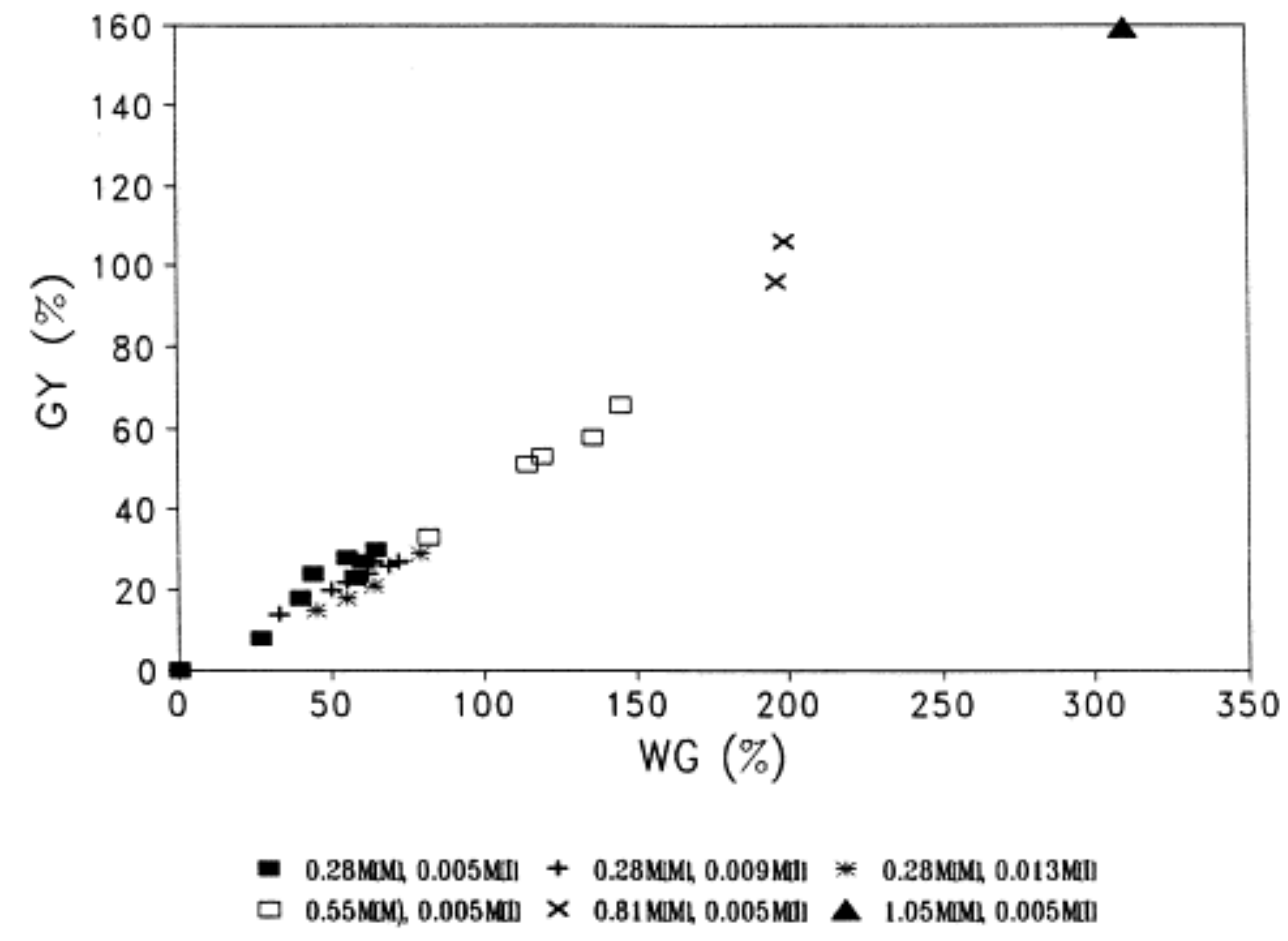

Fig. 7. Graft yield vs weight gain for the graft copolymerization of methyl acrylate onto SBS initiated by AIBN in chloroform. [SBS] $=23 \mathrm{~g} / \mathrm{l}, t=3-12 \mathrm{~h}, 63^{\circ} \mathrm{C}$. 


\subsubsection{Fraction of SBS which participates in graft copolymerization}

It is found that the entire reaction mixture dissolves in acetone when the weight gain exceeds $60 \%$. Since acetone is a non-solvent for SBS, then no unreacted SBS may be present in the reaction system; every SBS polymer molecule now has monomer molecules attached to it. A similar conclusion has been reached for the graft copolymerization of methyl methacrylate onto SBS ${ }^{19}$ and this also agrees with the work of Huang and Sundberg 1, 2, 3, 4 who found that every polybutadiene molecule was grafted.

\subsubsection{Retardation effect}

As noted above, the weight gain, and the conversion, depends on the concentration of SBS; as the amount of SBS increases the weight gain decreases, i.e., the reaction is retarded by adding more backbone polymer into reaction system. Fig. 8 shows a plot of the conversion as a function of concentration of SBS for the graft copolymerization reaction in chloroform initiated by both BPO and AIBN. The graft efficiency increases when a higher concentration of SBS is used; Fig. 9 shows the relationship between the graft yield and weight gain with different concentration of SBS for the graft copolymerization in chloroform initiated by both BPO and AIBN. A similar retardation effect has been observed by Cameron ${ }^{5,6,7,8}$ and in this laboratory for the reaction of methyl methacrylate with polybutadiene and SBS. ${ }^{19}$

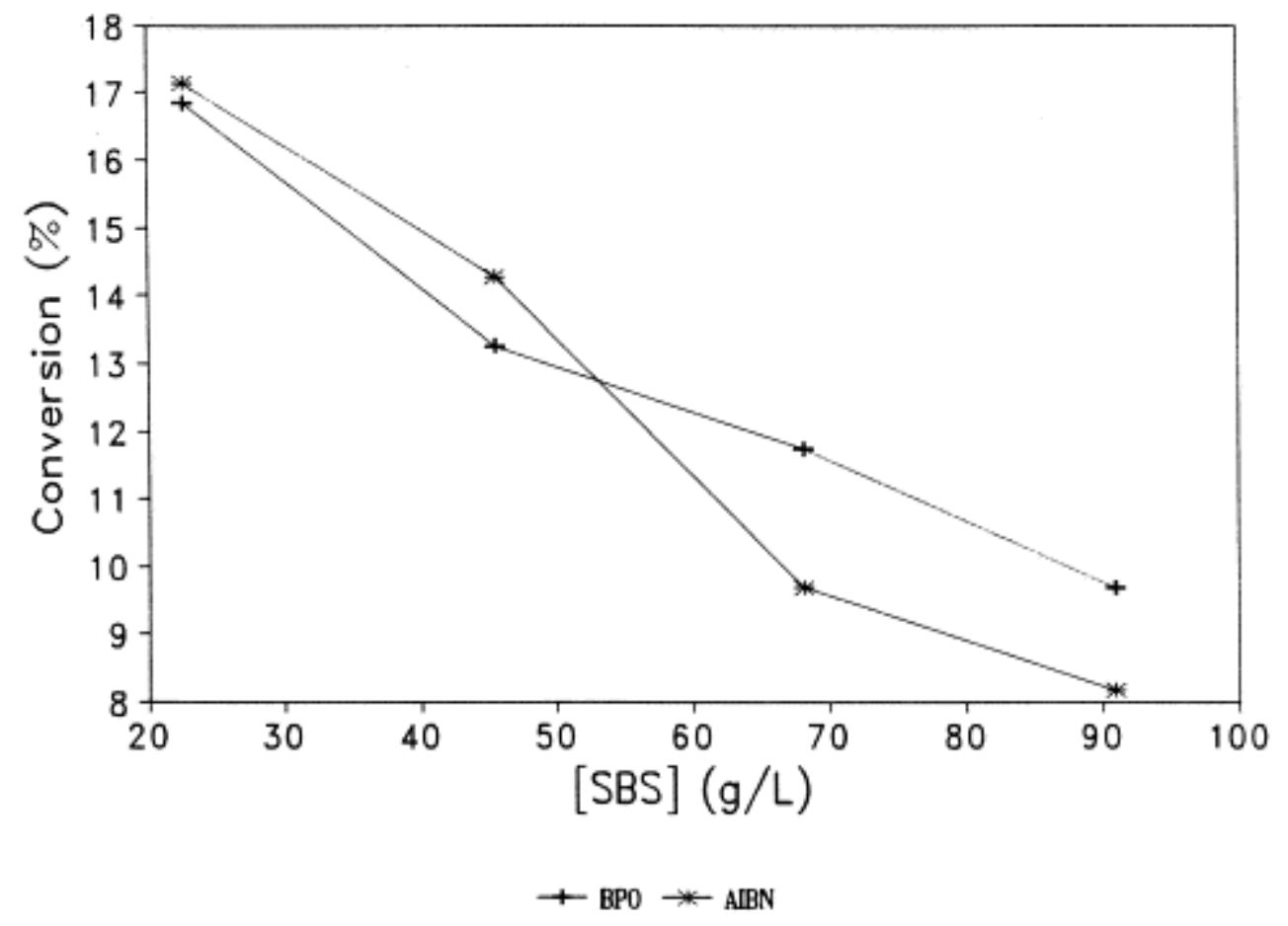

Fig. 8. Conversion as a function of [SBS] for the graft copolymerization of methyl acrylate onto SBS in chloroform. $[\mathrm{l}]=0.047 \mathrm{M},[\mathrm{MA}]=0.28 \mathrm{M}, 6 \mathrm{~h}, 63^{\circ} \mathrm{C}$. 


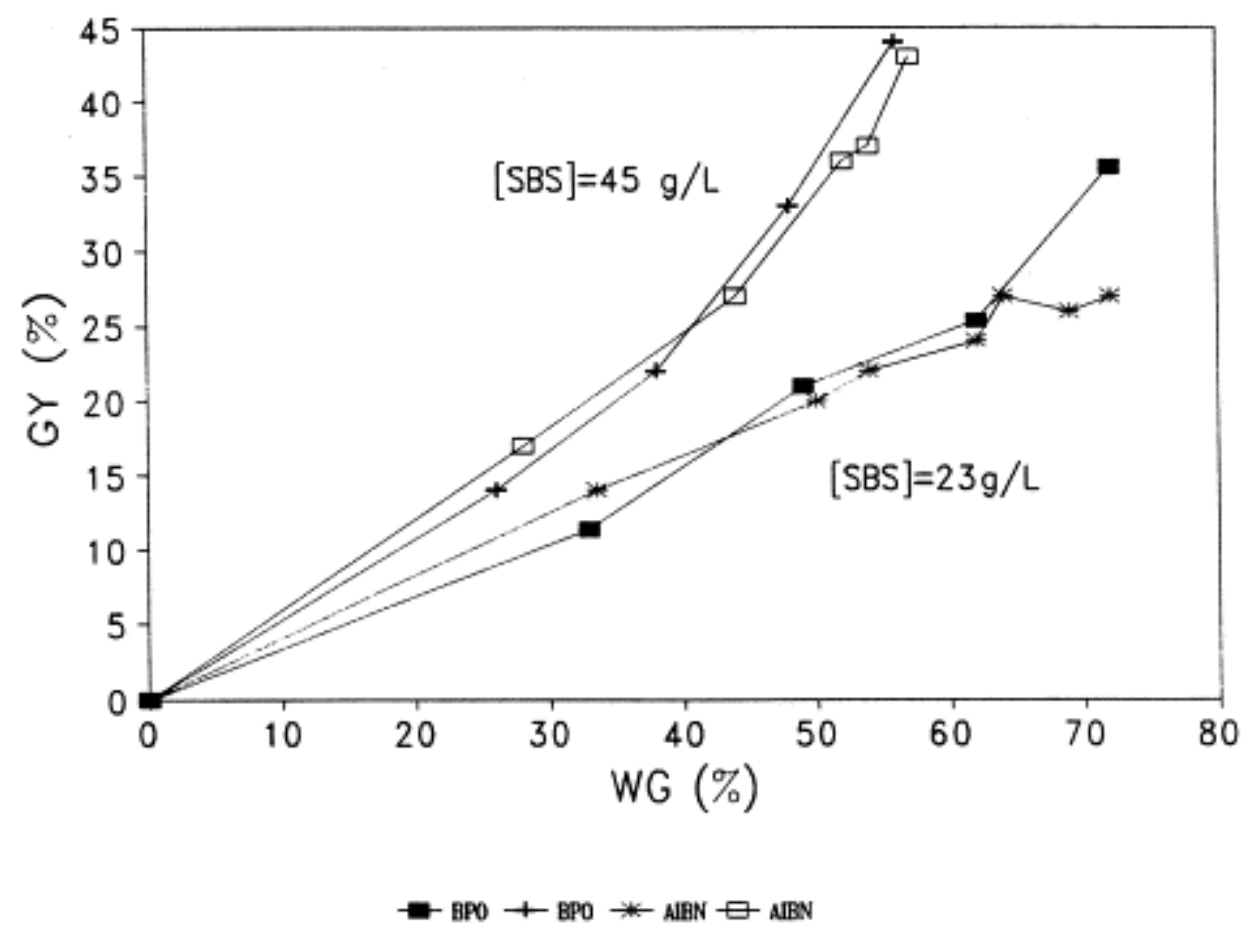

Fig. 9. Graft yield vs weight gain and [SBS] for graft copolymerization of methyl acrylate onto SBS in chloroform. [methyl acrylate] $=0.28 \mathrm{M},[\mathrm{l}]=0.0091 \mathrm{M}, 3-12 \mathrm{~h}, 63^{\circ} \mathrm{C}$.

\subsubsection{Solvent effect}

There is a small effect on the weight gain and conversion but a significant effect on graft yield and graft efficiency for both BPO and AIBN when the solvent is changed from chloroform to THF; this is shown in Table 1. AIBN shows a higher weight gain (and a corresponding higher conversion) than BPO in both solvents but both initiators have similar graft yields and graft efficiencies. Chloroform is a much more effective solvent than THF for the graft copolymerization of methyl acrylate onto SBS.

Table 1. Solvent and initiator effect for graft copolymerization of methyl acrylate onto SBS

\begin{tabular}{lllll}
\multicolumn{1}{c}{ Initiator/solvent } & \multicolumn{1}{c}{ Weight gain (\%) } & Conversion (\%) & Graft yield (\%) & Graft efficiency (\%) \\
$\mathrm{BPO} / \mathrm{CHCl}_{3}$ & 95 & 48 & 49 & 51 \\
$\mathrm{BPO} / \mathrm{THF}$ & 79 & 40 & 12 & 15 \\
$\mathrm{AlBN} / \mathrm{CHCl}_{3}$ & 116 & 59 & 52 & 45 \\
$\mathrm{AlBN} / \mathrm{THF}$ & 113 & 57 & 16 & 14
\end{tabular}

[SBS] $=23 \mathrm{~g} / \mathrm{l}$, [methyl acrylate $]=0.55 \mathrm{M},[\mathrm{I}]=0.0047 \mathrm{M}, 6 \mathrm{~h}, 63^{\circ} \mathrm{C}$.

\subsubsection{Site at which graft copolymerization occurs}

Graft copolymerization may either occur on the styrene portion or the butadiene portion of the polymer. We have previously shown that graft copolymerization does not occur onto polystyrene by radical processe ${ }^{20}$ and thus the reaction must occur onto the butadiene portion of the copolymer. There are two pathways by which monomers may be grafted onto a butadiene moiety in either a butadiene homopolymer or a copolymer; addition of a macroradical to the double bond or removal of an allylic hydrogen atom by the primary radical formed from the initiator and the subsequent addition of monomer units at that site. Huang and Sundberg1, 2,3,4 have concluded based upon their kinetic 
investigation of the graft copolymerization reaction that the course of the reaction depends upon the relative reactivities of the monomer versus that of the macroradical. Since a methacrylate ester would be more reactive monomer than an acrylate, they suggested that the methacrylate ester may add directly to a radical site which is formed by the action of the primary radical. On the other hand, the lower reactivity of an acrylate ester makes it more likely that a macroradical addition reaction will occur. In the case of methyl methacrylate, we have shown by infrared spectroscopy that the changes in the $\mathrm{C}-\mathrm{H}$ out-of-plane bending modes are most consistent with an allylic addition of the monomer. For the acrylate the fact that both AIBN and BPO will successfully initiate the graft copolymerization argues for the presence of a macroradical addition scheme since the resonance-stabilized AIBN radical is wellknown to be unable to remove a hydrogen atom. ${ }^{21,22}$ Infrared spectroscopy confirms this mode of interaction. The infrared spectra of virgin SBS and a graft copolymer in which methyl acrylate is added into SBS are shown in Fig. 10; three regions in these spectra are of interest, the olefinic $\mathrm{C}-\mathrm{H}$ stretching frequency just above $3000 \mathrm{~cm}^{-1}$, the $\mathrm{CH}_{2}$ bending vibration at about $1450 \mathrm{~cm}^{-1}$, and the $\mathrm{C}-\mathrm{H}$ out-ofplane bending frequency at $900 \mathrm{~cm}^{-1}$. The ratio of the $\mathrm{C}-\mathrm{H}$ out-of-plane bending absorbance to that of the $\mathrm{CH}_{2}$ bending absorbance falls for methyl acrylate while it is almost unchanged for methyl methacrylate; likewise the ratio of the $\mathrm{C}-\mathrm{H}$ stretching absorbance to that of the $\mathrm{CH}_{2}$ absorbance falls for the acrylate while it shows little change for the methacrylate. These indicate that the number of double bonds decreases for the acrylate which confirms that addition to the double bond occurs.

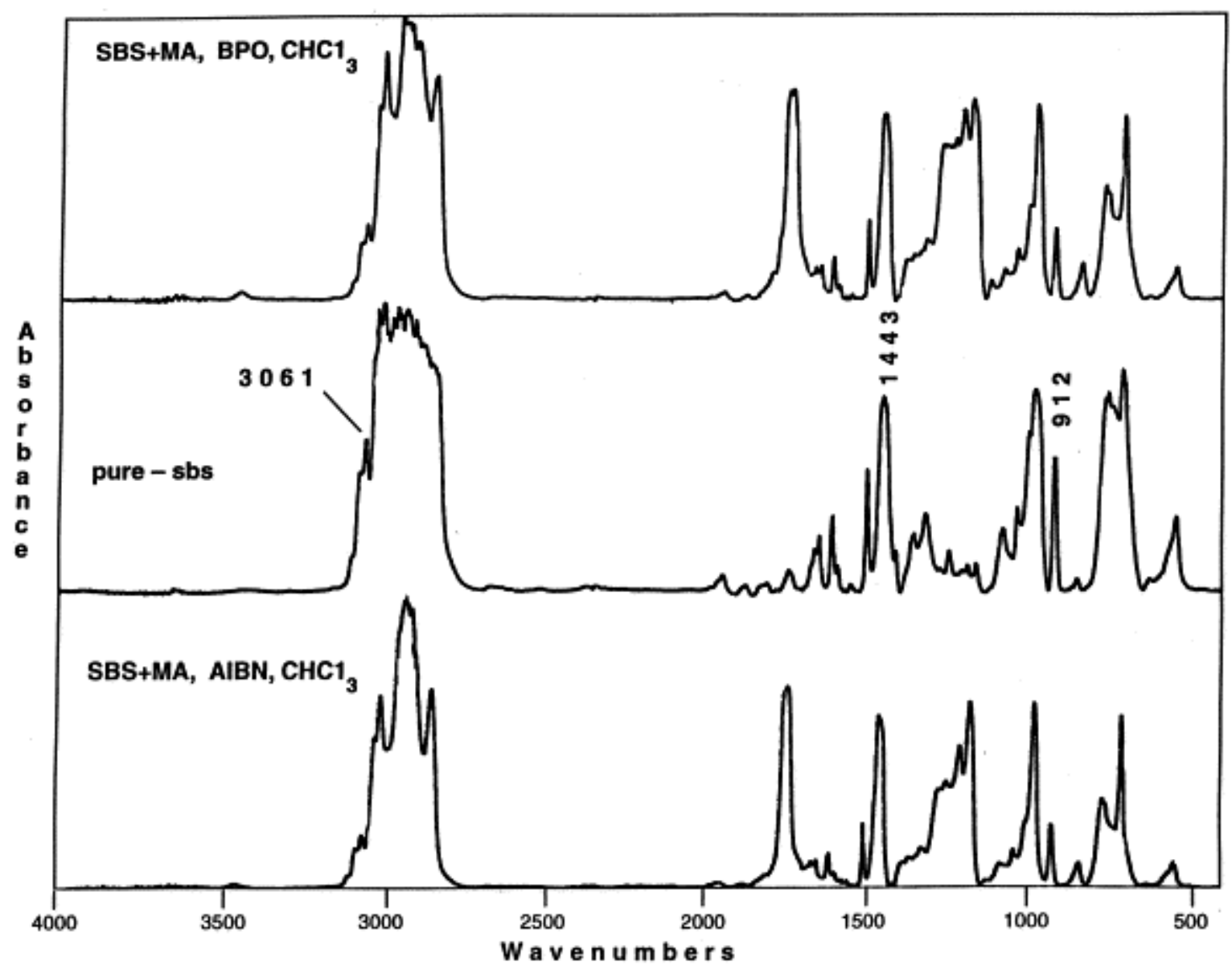

Fig. 10. Infrared spectra of SBS and the graft copolymer of SBS with methyl acrylate. Top, BPO initiation; middle, virgin SBS; bottom, AIBN initiation. 


\subsubsection{Comparison between methyl methacrylate and methyl acrylate}

Methyl methacrylate is a more reactive monomer than is methyl acrylate due to the hyper-conjugation of the methyl group attached to the double bond but both may participate in the graft

copolymerization reaction. Table 2 gives the weight gain, conversion, graft yield and graft efficiency for both monomers under similar reaction conditions. It is striking that all of these terms are larger for the less reactive monomer, methyl acrylate. The most likely explanation is that the reaction pattern, which is controlled by the reactivity of monomer, controls the extent of reaction.

Table 2. Comparison of the graft copolymerization of methyl methacrylate and methyl acrylate onto SBS in chloroform

\section{Methyl methacrylate ${ }^{a}$}

Weight gain (\%)

Conversion (\%)

Graft yield (\%)

Graft efficiency (\%)
126

34

40

32
Methyl acrylate ${ }^{b}$
57

84

51

${ }^{\mathrm{a}}[\mathrm{SBS}]=22.2 \mathrm{~g} / \mathrm{l},[\mathrm{MMA}]=0.82 \mathrm{M},[\mathrm{BPO}]=0.0045 \mathrm{M}, 6 \mathrm{~h}, 65^{\circ} \mathrm{C}$.

${ }^{\mathrm{b}}[\mathrm{SBS}]=22.7 \mathrm{~g} / \mathrm{l},[\mathrm{MA}]=0.81 \mathrm{M},[\mathrm{BPO}]=0.0047 \mathrm{M}, 6 \mathrm{~h}, 63^{\circ} \mathrm{C}$.

\subsection{Graft copolymerization of acrylic acid and methacrylic acid onto styrene-butadiene} block copolymer

\subsubsection{Amount of grafted SBS}

There are significant differences between the graft copolymerization of the esters and the free acids. For both methyl methacrylate and methyl acrylate, when the conversion of monomer to homopolymer and graft copolymer exceeds 50\%, no unreacted SBS may be recovered, i.e., every polymer chain has ester units attached. For the graft copolymerization of the free acids this is not true and only a fraction of the SBS which has been charged to the container has participated in graft copolymerization. The second major difference is that both AIBN and BPO are equally effective in the initiation of graft copolymerization for both methacrylic acid and acrylic acid. We shall first discuss the extent to which the SBS participates in the graft copolymerization reaction. Using both separation schemes noted in the experimental section it was determined that the amount of ungrafted SBS shows no dependence upon the amount of monomer; there is some dependence on the identity of the initiator for the reaction with acrylic acid but both initiators give the same results for reaction with methacrylic acid. There is a small difference in recoveries for the two separation schemes and this reflects the difficulty of the separation. The results are shown in Table 3.

Table 3. Recovery of ungrafted SBS from graft copolymerization of methacrylic acid and acrylic acid onto SBS in chloroform initiated by BPO and AIBN

BPO initiation AIBN initiation

Methacrylic acid

[methacrylic acid]

0.28

0.55

0.28

0.55

\% Recovery ( $\mathrm{MeOH} / \mathrm{CHCl}_{3}$ separation)

82

85

82

75

$\%$ Recovery $\left(\mathrm{H}_{2} \mathrm{O} / \mathrm{CHCl}_{3}\right.$ separation)

72

72

78

77 
BPO initiation

AIBN initiation

Acrylic acid

[acrylic acid]

0.35

0.68

0.35

0.68

$\%$ Recovery ( $\mathrm{MeOH} / \mathrm{CHCl}_{3}$ separation)

65

73

52

58

\% Recovery $\left(\mathrm{H}_{2} \mathrm{O} / \mathrm{CHCl}_{3}\right.$ separation)

72

70

54

53

[SBS] $=23.5 \mathrm{~g} / \mathrm{l},[\mathrm{l}]=0.0047 \mathrm{M}, t=2 \mathrm{~h}, T=63^{\circ} \mathrm{C}, \mathrm{CHCl}_{3}=20 \mathrm{ml}$.

The observation that only a small portion of the polymer participates in the graft copolymerization reaction is probably due to the insolubility of the graft copolymer and the homopolymers of the acids in the reaction solvent, chloroform. Since the extent of reaction does not depend upon the identity of the initiator, the reaction likely involves the polymeric macroradical as a reactant. As the macroradical grows in size, it will become insoluble in chloroform and begin to precipitate from the solution. The precipitating macroradical may either continue to add monomer units in a heterogeneous reaction or it may react with a butadiene double bond, also in a heterogeneous reaction. The heterogeneity of the reaction is likely the reason for the small amount of SBS which reacts.

The amount of SBS which does not react is independent of the identity of the initiator for methacrylic acid but shows an initiator dependence for acrylic acid. Methacrylic acid is a more reactive monomer and thus will be easily converted into macroradical, regardless of the initiator. Acrylic acid is a less reactive monomer so the formation of the macroradical may depend upon the initiator; the macroradical from acrylic acid is more reactive than that from methacrylic acid and therefore a larger portion of the SBS reacts.

\subsubsection{Extent of graft copolymerization of methacrylic acid and acrylic acid onto SBS}

There are two ways in which one may measure the graft yield, using the starting mass of SBS or using only the amount which actually reacts. The data is tabulated in both ways in Table 4; the apparent graft yield is calculated using the mass of SBS which was charged to the reaction vessel while the real graft yield uses only the mass of SBS which participates in the graft copolymerization reaction.

Table 4. Apparent and real graft yields for the graft copolymerization of methacrylic acid and acrylic acid onto SBS in chloroform

BPO initiation

Methacrylic acid

[methacrylic acid]

Apparent graft yield, \%

Real graft yield, \% (MeOH separation)

Real graft yield, \% (water separation)

Acrylic acid

[acrylic acid]

Apparent graft yield, \%

Real graft yield, \% (MeOH separation)
0.28

37

210

140

0.35

41

125
0.55

50

250

200

0.68

55

253
AIBN initiation

0.28

0.55

46

170

160

$70 \quad 160$

$0.35 \quad 0.68$

$52 \quad 120$

$104 \quad 285$ 


$\begin{array}{lcccc} & & \text { BPO initiation } & & \text { AlBN initiation } \\ \text { Real graft yield, \% (water separation) } & 60 & 250 & 125 & 260\end{array}$

Both the apparent and real graft yields show a dependence on the concentration of monomer; this is the expected behavior since the greater the concentration of monomer, the more macroradicals will form and the more opportunity there will be for reaction of a macroradical with a butadiene unit in an SBS chain. Just as in the data on the amount of SBS which is involved in graft copolymerization, there is some amount of scatter in the data and this reflects the difficulty of separation of the graft copolymer. This research group has previously examined the photochemically induced graft copolymerization of methacrylic acid onto SBS; these graft yields are comparable to those observed in the photochemical study and one may conclude that both means of initiation are equally effective.

\subsubsection{Site of graft copolymerization}

Infrared spectroscopy provides a definitive answer for the site of addition for both methyl methacrylate and methyl acrylate; the infrared results are more ambiguous for the graft copolymerization of the acids. The strong $\mathrm{O}-\mathrm{H}$ stretching vibration near $3500 \mathrm{~cm}^{-1}$ interferes with the observation of the olefinic $\mathrm{C}-\mathrm{H}$ stretch just above $3000 \mathrm{~cm}^{-1}$ and the very high graft yields render many of the SBS vibrations difficult to observe in these spectra. It appears that the $\mathrm{CH}_{2}$ bending vibration at $1449 \mathrm{~cm}^{-1}$ is little changed while the $\mathrm{C}-\mathrm{H}$ out-of-plane bending modes seem to be diminished in intensity and this is in accord with the addition of a macroradical addition to the double bond. It is also true that the changes are small and by themselves do not provide definitive evidence of the site of graft copolymerization. When combined with the initiator dependence, this data does indicate that the reaction proceeds by addition of the macroradical to the double bond of the butadiene.

\subsubsection{Mode of reaction}

The graft copolymerization reaction of methyl methacrylate proceeds by addition of monomer to an allylic radical while for the other three monomers which have been studied, methyl acrylate, acrylic acid, and methacrylic acid, reaction occurs by addition of a macroradical to the double bond. One might expect that all methacrylates will react by the same process yet this data refutes this assertion. Mayo ${ }^{23}$ has stated that a monomer which is readily initiated gives rise to a polymeric radical which has low activity in subsequent steps and vice versa. This has been used by Huang and Sundberg to explain the difference between acrylates and methacrylates. Mayo's ordering is based upon the electron donating ability of the substituents adjacent to the double bond. Since $\mathrm{OCH}_{3}$ is a better electron donor than is $\mathrm{OH}$, the ester may be expected to be more reactive than is the acid.

\section{Conclusion}

Various vinyl monomers may be graft copolymerized onto the butadiene region of SBS. The solubility of the homopolymer in the reaction solvent has a role in the extent of reaction. Infrared spectroscopy will enable one to identify the site on the polymer at which graft copolymerization occurs and this enables the determination of the mode of the reaction. Surprisingly it is found that both methacrylic acid and acrylic acid react by way of the macroradical addition to the double bond of the polymer; this mode of addition has also been observed for methyl acrylate. The most reactive monomers, such as methyl methacrylate, add directly to radical sites which are formed on the polymer by the interaction of the polymer and the primary radical from the initiator. 


\section{References}

1 N.-J. Huang, D.C. Sundberg. Polym. J. Sci. Part A: Polym. Chem., 33 (1995), p. 2533.

2 N.-J. Huang, D.C. Sundberg. Polym. J. Sci. Part A: Polym. Chem., 33 (1995), p. 2551.

3 N.-J. Huang, D.C. Sundberg. Polym. J. Sci. Part A: Polym. Chem., 33 (1995), p. 2571.

4 N.-J. Huang, D.C. Sundberg. Polym. J. Sci. Part A: Polym. Chem., 33 (1995), p. 2587.

5 A. Brydon, G.M. Burnett, G.G. Cameron. J. Polym. Sci. Polym. Chem. Edn., 11 (1973), p. 3255.

6 A. Brydon, G.M. Burnett, G.G. Cameron. J. Polym. Sci. Polym. Chem. Edn., 10 (1974), p. 1011.

7 G.G. Cameron, M. Younus Quereshi. J. Polym. Sci. Polym. Chem. Edn., 18 (1980), p. 2143.

8 G.G. Cameron, M. Younus Quereshi. J. Polym. Sci. Polym. Chem. Edn., 18 (1980), p. 3149.

9 X. Dong, G. Geuskens, C.A. Wilkie. Eur. Polym. J., 31 (1995), p. 1165.

10 M. Suzuki, C.A. Wilkie. Polym. J. Sci. Part A: Polym. Chem., 33 (1995), p. 1025.

11 C. Deacon, C.A. Wilkie. Eur. Polym. J., 32 (1996), p. 451.

12 J.A. Chandrasiri, C.A. Wilkie. Polym. J. Sci. Part A: Polym. Chem., 34 (1996), p. 1113.

13 E. Uchida, Y. Uyama, Y. Ikada. Polym. J. Sci. Part A: Polym. Chem., 27 (1989), p. 527.

14 Y. Uyama, Y. Ikada. J. Appl. Polym. Sci., 41 (1990), p. 619.

15 K. Allmer, A. Hult, B. Ranby. Polym. J. Sci. Part A: Polym. Chem., 26 (1988), p. 2099.

16 K. Allmer, A. Hult, B. Ranby. Polym. J. Sci. Part A: Polym. Chem., 27 (1989), p. 1641.

17 K. Allmer, A. Hult, B. Ranby. Polym. J. Sci. Part A: Polym. Chem., 27 (1989), p. 3405.

18 K. Allmer, A. Hult, B. Ranby. Polym. J. Sci. Part A: Polym. Chem., 27 (1989), p. 3419.

19 D.D. Jiang, C.A. Wilkie. Polym. J. Sci. Part A: Polym. Chem., 35 (1997), p. 965.

20 Xue, T. J. and Wilkie, C. A., J. Polym. Sci. Part A: Polym. Chem., in press.

21 J.C. Bevington. J. Chem. Soc. London, 4 (1954), p. 3707.

22 Seymour, R. B. and Carraher, C. E., Jr, Polymer Chemistry, 3rd edn. Dekker, New York, 1992, p. 324.

23 F.R. Mayo, F.M. Lewis, C. Walling. J. Am. Chem. Soc., 70 (1948), p. 1529. 